\title{
Plant Photomorphogenesis in Canopies, Crop Growth, and Yield
}

\author{
Carlos L. Ballaré, Ana L. Scopel, and Rodolfo A. Sánchez \\ IFEVA, Departamento de Ecología, Facultad de Agronomía, Universidad de Buenos Aires, Avenida San Martín \\ 4453, Buenos Aires 1417, Argentina
}

\begin{abstract}
Shading can be a major source of stress for plants of many crop species. In crops grown as dense populations, shading is mostly caused by neighboring plants of similar size and genotype. In this paper we summarize the current state of knowledge on how plants use light signals for detecting and responding to the proximity of neighbors. We then discuss the agricultural and horticultural implications of the photocontrol of plant morphological plasticity in canopies, and we explore the consequences of interfering with light signaling among neighboring plants on plant growth, canopy productivity, and agronomic yield of greenhouse and field crops. Most examples used in the discussion are taken from research carried out with grain and vegetable crops, and their associated weeds.
\end{abstract}

\section{NEIGHBOR DETECTION IN PLANT COMMUNITIES}

\section{Signals}

Light is scattered within plant tissues and plant pigments absorb most of the ultraviolet $(\lambda<400 \mathrm{~nm})$ and visible $(400 \mathrm{~nm} \leq \lambda \leq 700 \mathrm{~nm})$ photons. In contrast, fewer far-red (FR; $\lambda>700 \mathrm{~nm}$ ) quanta are absorbed, and most of them exit the plant in the form of scattered radiation. Therefore, within plant canopies, the light environment is characterized by low levels of blue (B) and red (R) light (the visible wavelengths that are most absorbed by chlorophylls) and high levels of FR.

Changes in the $\mathrm{R}$ : FR ratio are used by plants to sense the proximity of neighboring individuals (for reviews, see Ballaré, 1994; Ballaré et al., 1992b; Sánchez et al., 1993). Taylorson and Borthwick (1969) first put forward the idea that R: FR sensing by phytochrome could provide a mechanism for seeds underneath vegetation canopies to perceive leaf shading. Thus, variations in R : FR caused by preferential absorption of $\mathrm{R}$ light by chlorophylls would shift the amount of phytochrome present as Pfr (the FR-absorbing form of phytochrome). The change in Pfr would provide a cellular signal that, being related to the degree of shading, could be used by seeds and plants in the understory to control developmental timing and morphogenesis. This idea has been supported by spectroradiometric studies in plant canopies (Holmes and Smith, 1977; Kasperbauer, 1971) and physiological experiments in controlled environments (Morgan and Smith, 1978; Taylorson and Borthwick, 1969).

Detailed field studies on the early development of even-aged canopies led to the discovery that seedlings begin to display morphological responses to the nearness of other plants well before they become shaded by their neighbors and that some of these responses are elicited by variations in the R : FR ratio (Ballaré et al., 1987, 1988; Casal et al., 1986). These findings were puzzling for two reasons. First, studies with horizontally placed, cosine-corrected light receivers, which had been used as a standard to characterize the light climate in canopies, had shown that the $\mathrm{R}$ : FR ratio changes little with canopy density when the leaf area index (LAI) is <1 (e.g., Ballaré et al., 1987; Holmes and Smith, 1977). Second, the possibility that variations in $\mathrm{R}$ : FR could elicit morphological responses in plants receiving full sunlight irradiances was not generally accepted at that time (Smith and

Received for publication 17 Mar. 1995. Accepted for publication 9 Apr. 1995. Some of the concepts stemmed from work supported by the Consejo Nacional de Investigaciones Científicas y Técnicas, the Antorchas Foundation (Argentina), and the Dept. of Forest Science, Oregon State Univ. This support is gratefully acknowledged. The cost of publishing this paper was defrayed in part by the payment of page charges. Under postal regulations, this paper therefore must be hereby marked advertisement solely to indicate this fact.
Whitelam, 1987). Ballaré et al. (1987) postulated that FR light backscattered by neighbors provides to each individual seedling an early warning signal of impending competition, which would trigger morphological responses before the onset of shading. Figure 1 shows how light scattering by plant tissues increases the fluence rate of FR received by vertically oriented internodes as the LAI of a seedling stand increases, and how this spectral shift precedes variations in photosynthetically active radiation (PAR) at the leaf level. The ability of plants to use reductions in the R : FR spectral balance to detect their neighbors remotely has now been demonstrated using several experimental approaches. These experiments involved manipulations of the light environment received by isolated plants growing under natural radiation (Ballaré et al., 1987, 1991b; Casal et al., 1987; Davis and Simmons, 1994; Novoplansky et al., 1990a), manipulations of the light environment in plant canopies (Ballaré et al., 1990), and the use of mutants deficient in R : FR sensing (Ballaré et al., 1992a; Casal and Kendrick, 1993).

Changes in photon fluence rate also convey information about the proximity of neighbors in plant stands. For plants growing underneath other vegetation, a change in the LAI of the canopy will cause variations in irradiance, which may serve as an input signal for the systems that control shade acclimation at different levels-from chloroplast physiology to whole-plant allometry (e.g., Blackman and Wilson, 1951; Björkman, 1981; Pearcy and Sims, 1994). Moreover, changes in light fluence rate may also function as early proximity signals in even-height canopies of broadleaf seedlings (Ballaré et al., 1991b), because fluence rate sensed by vertically oriented stems is more affected by changes in canopy density than the light environment of horizontal or diaphototropic leaves (Fig. 1).

Plants can sense fluence rate in two ways: 1) indirectly, by sensing changes in the availability of photosynthetic products (sugars), or 2) more directly, by sensing molecular signals closely related to the photoexcitation of chloroplast photosystems or a variety of specific informational photoreceptors (e.g., B-absorbing photoreceptors and phytochromes). Morphological responses to sucrose levels have been demonstrated (Bernier, 1988; Casal and Sánchez, 1992; Montaldi, 1969), and changes in ATP and NADPH production (caused by variations of light intensity) may elicit changes in photosystem stoichiometry and organization, with consequences on photosynthetic capacity (Chow et al., 1990). Morphological responses to irradiance changes sensed by phytochrome (Ballaré et al., 1991b) and a Babsorbing photoreceptor (Britz, 1990) have been documented in studies with de-etiolated plants grown under high PAR. Experimental evidence supports the suggestion that plants use fluence rate signals perceived by these photoreceptors in the process of neighbor detection, and that they respond with morphological changes that presumably improve their light-harvesting ability in crowded populations (see below).

\section{Information and responses}

Plants grown in populations are morphologically and functionally different from plants grown as isolated individuals. This plastic adjustment is triggered in part by mechanisms that use information about the canopy light environment, transduced by specific photoreceptors, to promote alternative developmental programs. In this section we will briefly review the evidence for the involvement of photomorphogenic mechanisms in the following responses to crowding: 1) increased height, 2) altered direction of shoot spreading, and 3) altered branching and assimilate allocation. These responses are extremely relevant to the processes discussed in the next section of this 


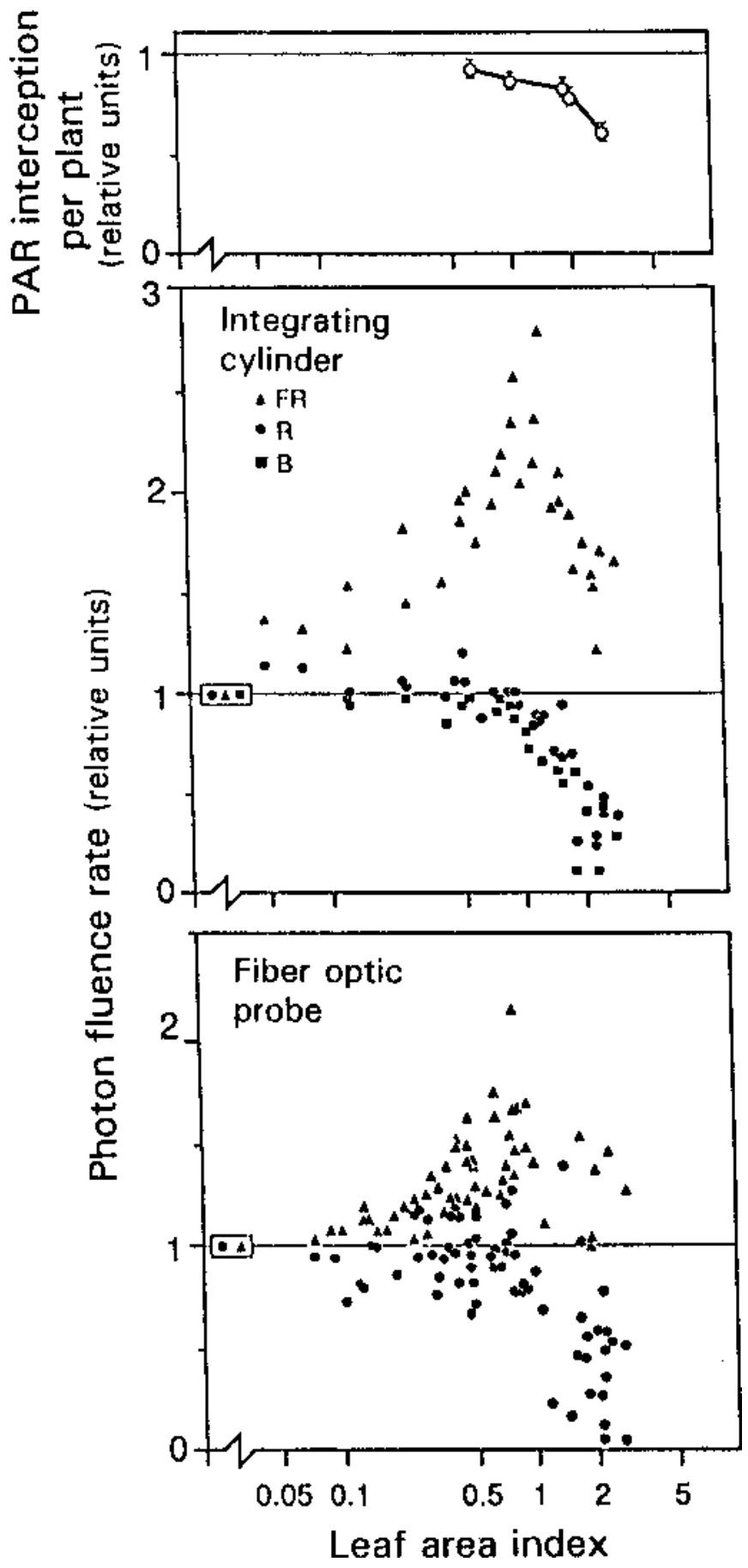

Fig. 1. Effects of increasing leaf area index (LAI) $\left(\mathrm{m}_{\text {leaf area }}^{2} / \mathrm{m}^{2}\right.$ soil area $)$ in evenheight canopies of dicotyledonous seedlings on light interception by leaves (top) and the light climate of the stems. Seedling stands of Sinapis alba L. and Daturaferox L. of differing densities and plant sizes were used to obtain the various LAI. The integrating cylinder collects sidelight received by the stem surface; the fiber optic probe collects light scattered within the stem tissue. All values are given relative to the measurements obtained for isolated plants or for $\mathrm{LAI} \approx 0$ (boxed symbols). $\mathrm{B}=$ blue; $\mathrm{FR}=$ far-red; $\mathrm{PAR}$ $=$ photosynthetically active radiation; $\mathrm{R}=$ red (from Ballaré, 1994; original data in Ballaré et al., 1991b).

review, and information about them has been gained in recent years using an interacting-plants approach (Aphalo and Ballaré, 1995) under realistic light conditions.

Height. Reductions of R : FR promote stem elongation. This action has been demonstrated for plants that received low levels of visible light (about $\leq 10 \%$ of full sunlight; Child and Smith, 1987; Kasperbauer, 1971; Morgan and Smith, 1978), and for plants grown under natural radiation supplemented with FR by using selectively reflecting mir- rors (Ballaré et al., 1987, 1991b). Furthermore, manipulative experiments with even-height stands of seedlings have provided direct evidence that the reduction in R : FR of light that impinges on the internodes (Fig. 1) can trigger an increase in stem elongation rate even if most of the leaf area is in full sunlight (Ballaré et al., 1990) (Fig. 2).

The decrease in fluence rate experienced by plant stems when the canopy begins to close (Fig. 1; LAI $\leq 1$ ) also promotes stem elongation during early stand development (Ballaré et al., 1991b) (Fig. 3). Changes in elongation rate triggered by $R$ : FR and fluence-rate signals are almost certainly beneficial for the individual plant, because in a rapidly growing canopy, a small difference in height would result in an inordinately large difference in PAR capture (e.g., Ballaré et al., 1988).

Direction. As plants grow in a crop canopy, they can sense the spatial distribution of their neighbors using fluence rate and $\mathrm{R}$ : FR signals perceived by B-absorbing photoreceptors and phytochromes. Irradiance gradients elicit phototropic movements of plant leaves (Koller, 1990) and stems (Iino, 1990), which presumably increase the light-harvesting capacity of plant shoots in horizontally patchy canopies. Novoplansky et al. (1990a) have presented evidence that alterations in the R:FR ratio of the scattered canopy light induce seedlings of the plagiotropic herb Portulaca oleracea L. to avoid neighboring plants, and Ballaré et al. (1992a) have shown that cucumber (Cucumis sativus L.) plants use phytochrome and a B-absorbing photoreceptor to remotely detect their neighbors and to elicit stem bending responses toward canopy gaps (Fig. 4).

Branching and assimilate allocation. Apart from being able to use light signals in controlling vertical and radial shoot expansion, plants have mechanisms that relay information about the canopy light environment into systems that control branching patterns and assimilate allocation to reproductive structures and vegetative storage organs (e.g., bulbs and roots). Thus, experiments under natural radiation have demonstrated that, in open grass canopies, the decrease in the R : FR ratio caused by neighboring plants can reduce branching (tillering)

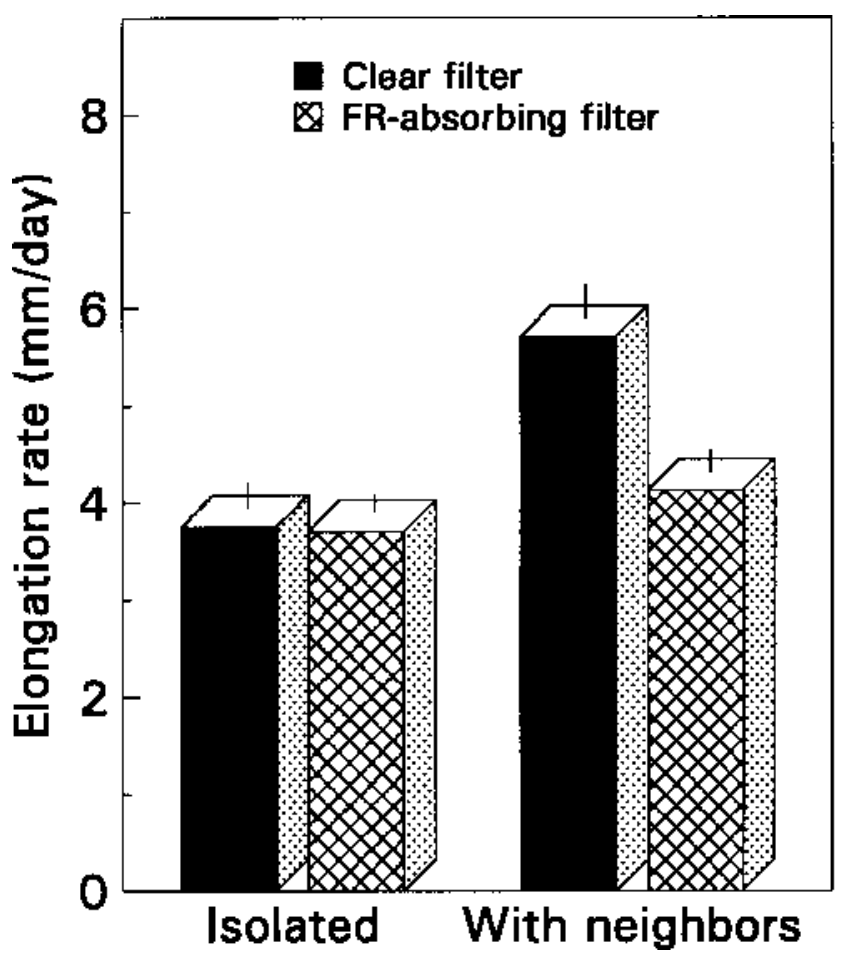

Fig. 2. Elongation response of Datura ferox first internode to the proximity of neighboring plants. Seedlings were placed at the center of an even-height canopy of leaf area index $\approx 0$.9. During the experiment, which ran for 3 days, the internodes were surrounded by annular cuvettes containing distilled water (clear filter) or a $\mathrm{CuSO}_{4}$ solution that absorbed far-red radiation and maintained the red : far-red ratio at $\approx 1.1$ (far-red-absorbing filter). The experiment was carried out with seedlings grown in individual containers, under natural summer radiation in Buenos Aires (adapted from Ballaré et al., 1990). 

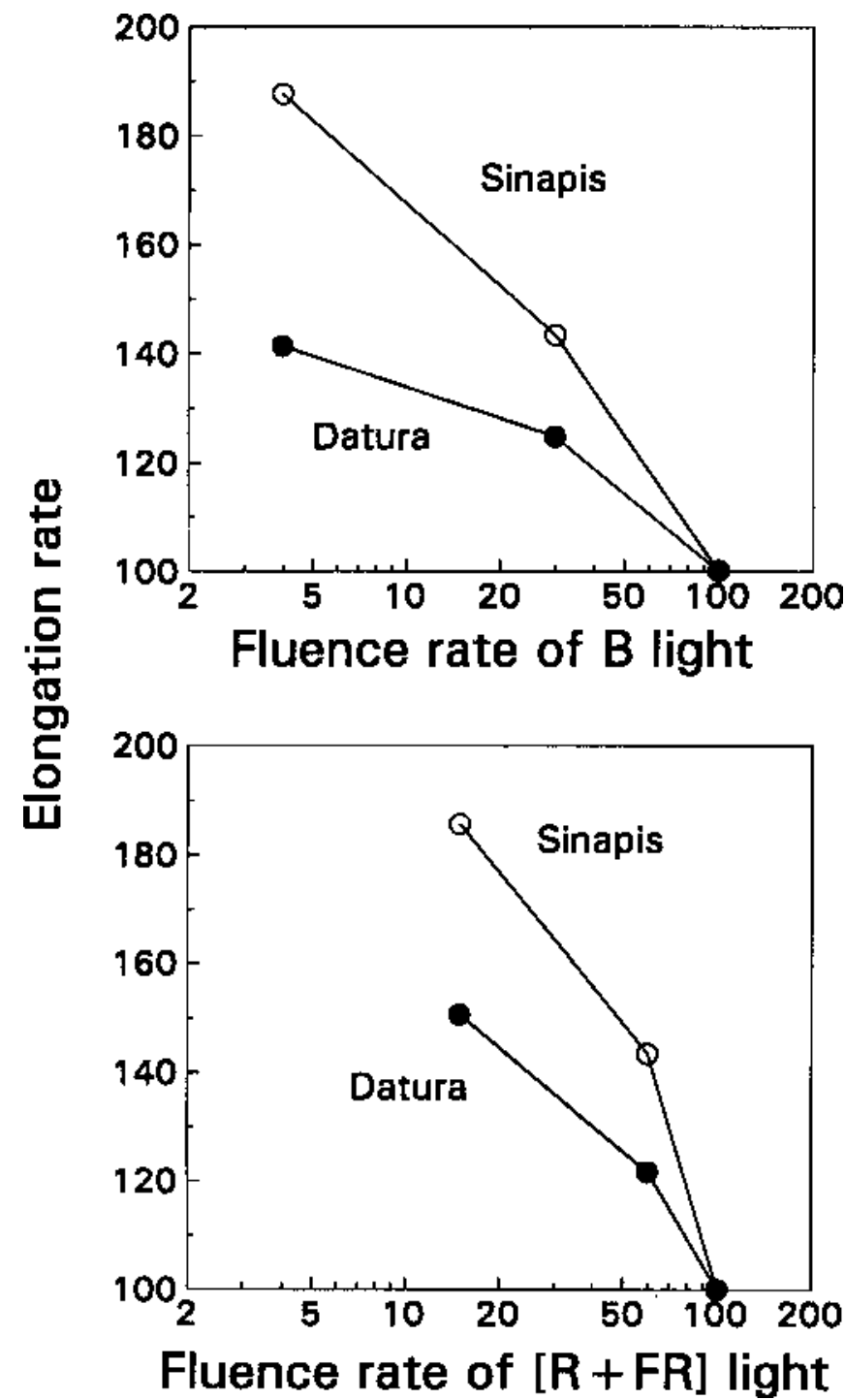

Fig. 3. Effects of reducing the fluence rate of blue (B) light at constant red (R) and far-red (FR) (top) or $\mathrm{R}+\mathrm{FR}$ radiation at constant $\mathrm{B}$ or $\mathrm{R}$ : FR (bottom) on internode elongation of Sinapis alba and Datura ferox seedlings. Seedlings were grown under sunlight and the light-filtering treatments were applied to the internodes only. Elongation rates (calculated after 1 week of treatment) and fluence rate values are given relative to control plants that had their internodes surrounded by a clear filter (from Ballaré et al., 1991b).

rate even if the production of new branches is not limited by the availability of PAR (Casal et al., 1986) (Fig. 5). Little is known about the importance of photomorphogenic mechanisms in controlling branching in dense stands, where the proximity of neighbors causes severe resource limitations and simultaneously alters many environmental variables (see Murphy and Briske, 1992). Natural- or simulated-leaf shading (i.e., low B and R, high FR) are more effective at inhibiting branching than comparable reductions of PAR obtained by means of neutral filters (Méthy et al., 1990; Solangaarachchi and Harper, 1987). This differential effect is most likely due to differences in $\mathrm{R}$ : FR between shading treatments, but direct responses to B irradiance (Barnes and Bugbee, 1991) may also play a role.

Plant developmental and allocation patterns can be affected strongly by stand density. Mondal et al. (1986a, 1986b) reported that some important developmental phases in onion (Allium cepa L.) crops, such as the transition to bulb scale production and bulb maturity, are promoted when planting density is increased. In radish (Raphanus sativus L.), high planting densities reduce growth of the storage root and accelerate flowering (Weston, 1982). Reduced assimilate allocation to roots with increased population density also was observed in red beet (Beta vulgaris L.) crops (Hole et al., 1984). In contrast, in other
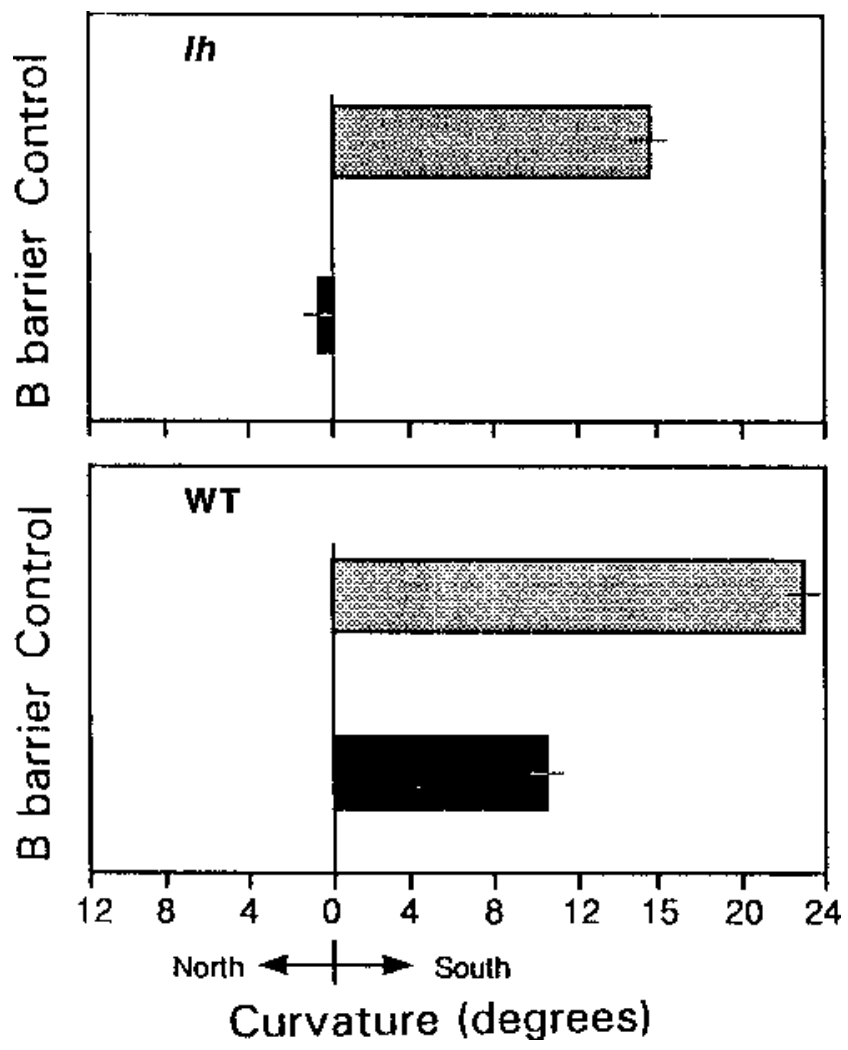

Fig. 4. Effects of the proximity of a green maize canopy and blue (B)-absorbing acetate filters (B barrier) on the orientation of the hypocotyls of wild type (WT) and $l h$-mutant seedlings of cucumber. Seedlings were grown in the field near Corvallis, Ore., for 2 days, $8 \mathrm{~cm}$ to the south of the edge of a dense maize crop. Seedlings of the $l h$-mutant (which lack immunochemically detectable phytochrome B) do not present phototropic responses to red : farred gradients, but display normal phototropism in response to B light. All the southward (i.e., "neighbor-avoiding") bending induced by the nearby maize canopy can be abolished by eliminating the B light irradiance gradient created by the presence of the canopy (cf. control vs. B barrier). Compared with $l h$ seedlings, WT seedlings display more intense bending in response to the proximity of the maize canopy, and a significant proportion of this bending cannot be accounted for by a response to B light (cf. control vs. B barrier) (from Ballaré et al., 1992a).

species, such as carrot (Daucus carota L.) and parsnips (Pastinaca sativa L.) (Currah and Barnes, 1979; Hole et al., 1983), assimilate allocation to storage organs appears to be less sensitive to the proximity of neighboring plants. In cassava (Manihot esculenta Crantz), proportional allocation to tubers is increased by intercropping with soybeans (Glycine $\max$ L.) (Tsay et al., 1987). The studies of Mondal et al. (1986a, 1986b) and Weston (1982) clearly suggest that photomorphogenic mechanisms are involved in the allocation responses of onion and radish plants.

Biomass allocation to reproductive structures is often affected by crowding (Harper, 1977). In crops as diverse as wheat (Triticum aestivum L.), cotton (Gossypium hirsutum L.), soybean, pepper (Capsicum annuum L.), and tomato (Lycopersicon esculentum Mill.), reproductive allocation is determined, among other things, by early abortion of flowers and young fruit. The rate of abscission of reproductive structures may be set by factors other than current assimilate supply. Heindl and Brun (1983) found that the abscission of reproductive structures in soybean can, in certain cases, be reduced under field conditions by lighting the lower canopy strata during flowering and early pod growth with $\mathrm{R}$ or white fluorescent light; this response to light was absent when the reproductive primordia were artificially shaded (Fig. 6). Evidence from studies with reproductive primordia cultured in vitro under various light regimes (Mor et al., 1980; Myers et al., 1987), and from controlled environment experiments involving local irradiation of soybean racemes (Myers et al., 1987), support the hypothesis (Heindl and Brun, 1983; Myers et al., 1987) that reproduc- 


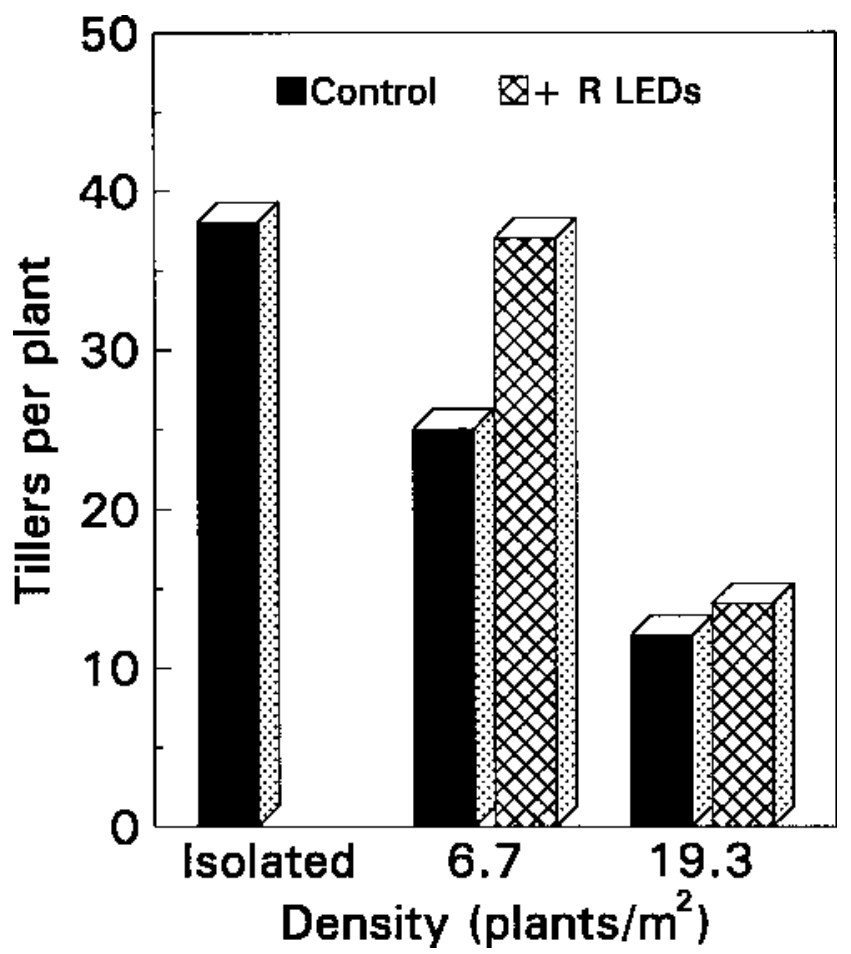

Fig. 5. The effect of population density and added red light [five light-emitting diodes (LED) at the base of each plant] on the number of tillers produced by Paspalum dilatatum Poir. plants after 60 days of treatment. Supplementary R light fully reversed the inhibition of tillering induced by the proximity of neighboring plants at low population densities but had almost no influence under high-density conditions. The experiment was carried out with plants grown in individual containers under natural radiation in Buenos Aires (adapted from Casal et al., 1986).

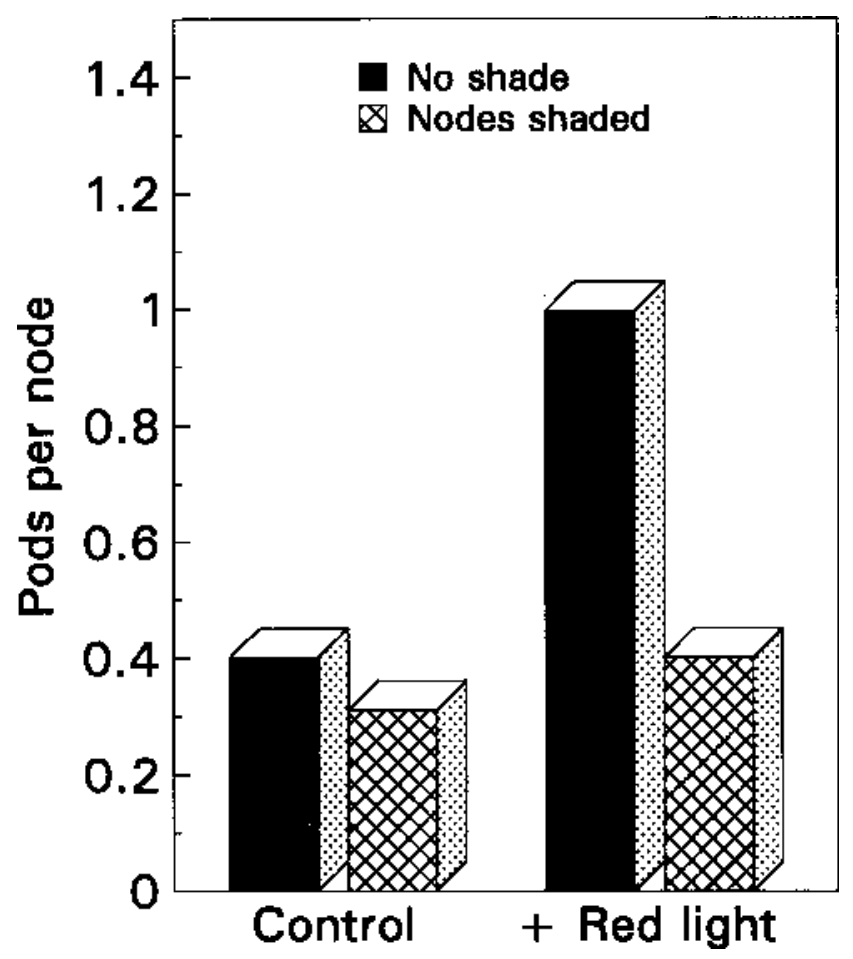

Fig. 6. Effect of lighting the lower canopy strata with red light on reproductive abscission in soybean. The supplemental light was applied for 3 weeks from full bloom through early pod growth; half of the nodes (first five trifoliate) were shaded using pieces of aluminum foil. About four flowers were produced on each node, and the bars indicate the average number of pods per node at maturity. The experiment was carried out in field plots in St. Paul, Minn., using the indeterminate soybean cultivar Evans (adapted from Heindl and Brun, 1983). tive abscission in the lower strata of soybean crops, and assimilate accumulation by young fruit, are modulated by photomorphogenic signals perceived by the primordia.

Photoresponses that involve reduced branching and altered allocation to reproduction and storage have been studied mostly in cultivated species. Predicting their ecological role in natural plant communities may be difficult, because the evolution of many of these responses (e.g., early flower and fruit abortion) is probably driven by multiple factors, which might involve such complexities as mutualistic interactions with other trophic levels (Ehrlén, 1991).

\section{PHOTOMORPHOGENESIS, GROWTH, AND YIELD}

What would be the agronomic consequences of interfering with the traffic of light signals among neighboring plants? Answering this question is important for three reasons: 1) to optimize lighting systems for intensive horticultural production, 2) to engineer crop strains with altered photomorphogenic responses, and 3) to aid in the design of complex multi-species or mixed-aged crop canopies, which likely will be favored as we move toward a more sustainable, know-howintensive agriculture. Yet, agronomists and plant biologists are just beginning to consider possible answers. Agronomists have often overlooked the significance of photomorphogenic processes in canopies. In turn, many plant biologists appear to have uncritically embraced the odd paradigm that all photomorphogenically driven proximity responses (sometimes teleologically called "shade-avoidance responses") are agriculturally wasteful. Briefly, the defenders of this paradigm maintain that growers will be better off with "blind" genotypes than with photomorphogenically responsive plants, because the former will not present any elongation response to the proximity of other crop plants, thereby saving a substantial amount of assimilates (Smith, 1992). We will discuss the significance of photomorphogenic signaling for crop growth and yield in two ways. First we will focus on individual plants, and discuss the effects of photomorphogenic responses to reduced fluence rate and $\mathrm{R}$ : FR ratio (i.e., alterations in light environment that mimic the proximity of other plants) on PAR interception, growth, and biomass allocation. Then we will highlight some of the complexities that are inherent to the population (or crop) level of organization.

\section{Isolated plants}

Long-term growth depends on development, which is photomorphogenically controlled. In the short term (minutes), variations in light conditions affect growth (biomass accumulation) rate essentially to the extent that light influences the rate of photosynthesis per unit leaf area. A glance at published action spectra of photosynthesis shows that all wavelengths within the 400- to 700-nm range are similarly effective in driving photosynthesis, and that quantum effectiveness falls off dramatically beyond $700 \mathrm{~nm}$ (Evans, 1987, and references therein). But short-term responses are arguably of little importance for ecologists and farmers, who are interested in long-term results, such as fitness, cumulative growth, or marketable yield. Growth during a given period of time can be visualized as the product of the amount of light intercepted during that period and the average efficiency of conversion of light energy into biomass. Only the conversion efficiency factor is related to the data obtained in standard gas-exchange determinations made on a per-unit-leaf-area basis, such as those used to obtain the action spectrum for photosynthesis. Körner (1991) has discussed the contribution of several plant characteristics as determinants of differences in plant growth rate between species, and highlighted the paramount influence of allometric factors (e.g., leaf weight ratio, specific leaf area), canopy architecture, and developmental factors (e.g., leaf plastochron, leaf duration). By affecting light interception, variations between species in these factors may completely mask the impact on growth of variations in photosynthetic rate (see also Küppers, 1994). All these plant characteristics are subject to light regulation. Thus, in the long-term (e.g., days, weeks), changes in light fluence rate and spectral distribution can influence growth (and growth responses to the light environment) strongly by altering the amount of biomass allocated to leaf tissue and the amount 
of leaf area produced per unit of biomass invested.

The involvement of phytochrome (Kasperbauer and Peaslee, 1973; Morgan and Smith, 1978) and blue-absorbing photoreceptors (Britz, 1990; Britz and Sager, 1990) in controlling these allocation responses is well documented. Therefore, although these photoreceptors do not participate in the photochemistry of C fixation, and may or may not have an influence on the stoichiometry and organization of the chloroplast photosystems (see Bradburne et al., 1989; Chow et al., 1990), they do influence growth responses to the light environment by controlling allocation processes that determine light interception. For instance, Bruggink and Heuvelink (1987) reported that a decrease of daily PAR from 400 to $300 \mathrm{~J} / \mathrm{cm}^{2}$ per day reduced net assimilation rate in greenhouse-grown tomato, cucumber, and sweet pepper plants. However, the relative growth rate remained almost unchanged due to an increase in the leaf area ratio (square centimeters per gram). The reasons for the increase in leaf area ratio with decreasing PAR were not investigated, but the results of Britz (1990) and Britz and Sager (1990) with soybean suggest that B light photoreceptors are involved in this response. Kwesiga and Grace (1986) reported that alterations in the light spectral distribution that simulated shadelight quality without affecting PAR caused an increase in the relative growth rate of seedlings of the tropical tree Terminalia ivoriensis A. Chev. The increase in relative growth rate was caused by a marked increase in leaf area ratio, which more than compensated for a decrease in net assimilation rate under simulated shadelight quality.

Photomorphogenic processes can influence light interception through mechanisms other than $\mathrm{C}$ partitioning or leaf area expansion. Changes in spectral quality, acting through phytochrome, affect branch and tiller inclination (Aphalo et al., 1991; Beltrano et al., 1991; Casal et al., 1990) and leaf angles (Decoteau and Friend, 1991b; McCormac et al., 1992). Fluence rate signals also affect branch and leaf inclination angles (Aphalo et al., 1991; Grime et al., 1986; Wilson and Greenberg, 1993). Light signals transduced by specific photoreceptors may control many aspects of developmental timing that influence light interception by the plant, such as the cessation of leaf production (e.g., in plants with photoperiodic induction of flowering) and leaf duration (Guiamet et al., 1989). We conclude this section with the idea that informational photoreceptors participate in controlling biomass accumulation through their influence on plant developmental timing, $\mathrm{C}$ allocation, and shoot architecture.

Allocation may be a nonzero game. Exposure to low $\mathrm{R}$ : FR ratios frequently results in plants with long internodes and low leaf : stem weight ratio (Morgan and Smith, 1978). Thus, it is frequently stated that stem growth responses to reduced R : FR may negatively affect plant (or crop) growth by taking up $\mathrm{C}$ that would otherwise be allocated to resource-harvesting organs (i.e., leaves and roots). This notion is largely based on information derived from experiments carried out under low light levels; indeed, even in growth chamber studies, the opportunity costs of light-induced height growth responses are not always evident, as the following examples demonstrate. Kasperbauer et al. (1984) exposed soybean plants to R and FR pulses at the end of the photoperiod in a growth chamber study. FR-treated plants had longer and heavier stems; leaf growth was not consistently altered, and root growth was slightly reduced by FR. Working with watermelon [Citrullus lanatus (Thunb.) Matsum \& Nakai] seedlings, Decoteau and Friend (1991b) found that the promotion of internode and petiole biomass accumulation caused by end-of-day FR for 7 consecutive days (compared to control seedlings or seedlings exposed to end-ofday R) was not accompanied by reduced leaf or root growth. Similar results were reported by López Juez et al. (1990a, 1990b) with tomato and cucumber. Moe et al. (1991) gave Campanula isophylla Moretti plants low-irradiance day extensions with fluorescent or incandescent lamps to induce flowering. There was little difference between treatments in time to flowering; however, in comparison with plants illuminated with fluorescent lamps $(\mathrm{R}: \mathrm{FR}=4.2)$, plants irradiated with incandescent lamps $(\mathrm{R}: \mathrm{FR}=0.7)$ had much longer stems, fewer branches, and a higher ( $\approx 24 \%$ more) total dry weight at flowering.

Fair comparisons of growth rate among light treatments in growth chamber studies are often difficult to obtain. Studies with amaranth (Amaranthus quitensis H.B.K.) plants grown under sunlight (Ballaré et al., 1991c) have shown that a localized reduction of R: FR at the stem level (which did not modify the light climate of the leaves) can increase internode elongation rate by a factor of two and dry-mater accumulation in the stems by $40 \%$ without having any negative impact on leaf or root growth. Indeed, total plant biomass is increased by the localized low R : FR treatment in this species (Fig. 7), presumably through a feedback control over photosynthesis (e.g., reduction in sink limitation). In a complementary series of experiments (Ballaré et al., 1991c), amaranth plants were grown under $\mathrm{CuSO}_{4}$ filters, which dramatically increased the $\mathrm{R}$ : FR ratio received by the shoots by preferentially absorbing FR radiation. When isolated plants were grown under the filters, the minus-FR treatment had no effect on biomass or biomass distribution (in comparison with a control employing neutral filters that transmitted similar PAR levels). In contrast, when whole amaranth stands (instead of isolated plants) were used in the experiments, the FR-absorbing filters caused a large reduction of canopy height and biomass accumulation in the stems. A likely interpretation of this
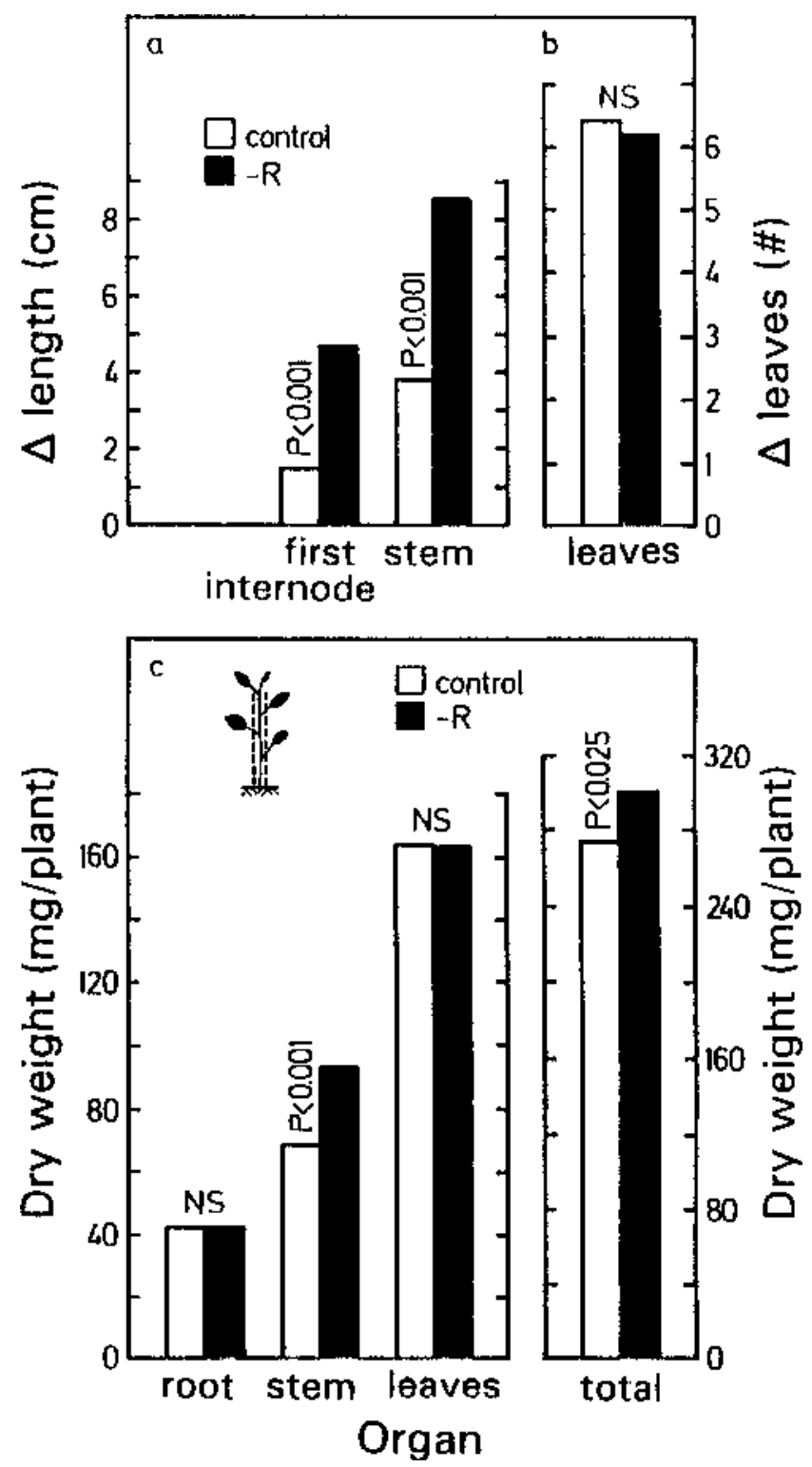

Fig. 7. Effect of reducing the fluence rate of red light received by stems of amaranth (Amaranthus quitensis) seedlings on plant growth and dry weight distribution. The experiments were carried out in a greenhouse with no supplemental lighting during the summer in Buenos Aires. Seedlings were exposed to the treatments for four consecutive days. The localized minusred treatment promoted internode elongation by a factor of $\approx 2$; the rate of leaf appearance was not affected. The bars indicate biomass present in the various organs at the end of the experiments. The level of significance is indicated for each difference; NS $=$ not significant $(P>0.05)$ (adapted from Ballaré et al., 1991c). 
result is that the very high $\mathrm{R}$ : FR ratios effectively negated the phytochrome-mediated neighbor detection mechanism in the amaranth stands, thus preventing elongation responses to crowding. However, contrary to the "zero-game" hypothesis, crop root growth or leaf growth were not promoted by filtering out the FR. Indeed, total crop biomass was reduced under the minus-FR treatment (Ballaré et al. 1991c).

With the many limitations of experiments in which FR levels received by the whole shoot are altered, other studies also suggest that $\mathrm{C}$ assimilation rate can be increased as a consequence of photomorphogenic responses triggered by low R : FR ratios. Supplementary FR applied during the photoperiod to plants of water hyacinth [Eichhornia crassipes (Mart.) Solms] in a greenhouse stimulated petiole elongation and increased the rate of photosynthesis per unit leaf area (Méthy and Roy, 1993). Working in large, walk-in growth rooms, Warrington et al. (1988) reported that adding FR to the light received by plantlets and seedlings of three species of conifers greatly promoted shoot elongation, increased dry weight accumulation in the stem and new needles, and increased total plant dry weight by $20 \%$ to $30 \%$. The increased growth rate under low R: FR ratios was attributed to reduced mutual shading of adjacent leaves and increased light interception, resulting from photomorphogenically induced increases in internode length. Additional information on the growth consequences of altered photomorphogenesis at high PAR has been gained by using colored soil covers. Kasperbauer and Hunt (1992) found that cotton seedlings grown outdoors over a "green" soil cover that decreased the R : FR ratio had slightly longer internodes and heavier shoots, similar root biomass, and significantly higher $(10 \%)$ total biomass than seedlings grown over a "red" cover. Both types of covers back-reflected similar PAR levels (which is often not the case when comparisons involve treatments where plants are grown over highly reflective white covers). Growth chamber studies with the same cotton variety had shown reduced root growth (and total biomass) in response to end-of-day FR pulses (Kasperbauer and Hunt, 1992).

We conclude this section with the hypothesis that, in terms of growth of resource-harvesting organs, the C-saving benefits of abolishing height growth responses to neighbor-proximity signals are likely to be small or nil, at least for plants grown under high PAR. In some cases, rapid stem growth does appear to stimulate total growth either by stimulating net photosynthesis per unit leaf area, which might be a consequence of increased sink activity (Ballaré et al., 1991c), or by increasing light interception, which might result from an altered pattern of light penetration into the lower canopy strata (Warrington et al., 1988).

Allocation to harvestable organs is photomorphogenically controlled. For most crops it is the biomass deployed into some storage organ (roots, tubers, bulbs, fruits, seeds) that constitutes the objective of production. Photomorphogenic mechanisms can affect the harvest index in various ways. In cereals and in many horticultural crops, proximity signals that affect branching will influence the number of flowers or inflorescences produced, thereby affecting potential harvest index. In cereals grown in high-input environments, the depression of tillering (induced, for example, by low $\mathrm{R}$ : FR ratios) may be beneficial, because it would reduce the number of secondary and tertiary tillers (Casal, 1988) that usually contribute little to seed yield and depress the harvest index (Bugbee and Salisbury, 1989; Donald, 1968). If this suggestion is correct, genotypes in which branching is very sensitive to neighbor-proximity signals would be expected to yield more than regular varieties, and light conditions that disturb the neighbor-detection mechanisms (e.g., very high $\mathrm{R}$ : FR ratios) would be expected to result in low harvest indexes. The reverse may be true in other agronomic conditions (Kirby and Faris, 1972) or for other crop species. For instance, rose (Rosa hybrida L.) bushes grown under fluorescent films that increased the R : FR ratio were more branched and had more growing floral buds per branch than plants grown under control films that transmitted similar PAR levels without altering the $\mathrm{R}$ : FR ratio. This reduced apical dominance was accompanied by an increase in flower yields (Novoplanksy et al., 1990b). The same fluorescent films increased yield in tomato, but yield components were not analyzed. Some authors have expressed the view that reduced branching (e.g., as induced by end-of-day FR pulses) is economically desirable in glasshouse-grown tomato, because side-shoot growth wastes assimilates and depresses fruit yield (Tucker, 1975). Indeed, studies with field-grown, irrigated plants have shown increased fruit counts and yield over colored surfaces that reflect low $\mathrm{R}$ : FR ratios in tomato and tobacco (reviewed by Kasperbauer, 1992). The physiological bases of these responses are difficult to establish, however, because, in addition to altering spectral quality, the mulches also influenced PAR levels and soil temperatures (Decoteau et al., 1989; Kasperbauer, 1992, and references therein).

As discussed earlier, photomorphogenic mechanisms might also affect the harvest index by controlling the abortion of reproductive structures, thereby affecting the number of sinks for assimilate storage. In high-input cropping environments, genotypes in which reproductive abortion is less affected by $\mathrm{R}$ : FR might have a higher potential harvest index. However, it is not clear whether 1) the photomorphogenic control of reproductive abortion is a widespread phenomenon or 2) an increase in sink capacity will be accompanied by increased yield, because source limitations may come into play during the fruit-filling period (see Ballaré et al., 1992b; Shibles et al., 1987).

In many crops, it is the assimilates allocated to vegetative storage organs that determines harvestable yield. The work of Weston (1982) and Mondal et al. (1986a, 1986b) (see above) suggests that there is scope for increasing yields of root and bulb by influencing developmental and allocation responses to crowding, which may be triggered photomorphogenically. Kasperbauer (1992) reported results of a field experiment showing that radish plants grown over mulches that reflected light with a $\mathrm{R}$ : FR ratio of 1.03 had higher root : shoot ratios and larger roots than plants grown over mulches providing $\mathrm{R}: \mathrm{FR}$ ratios of 1.00 or 0.78 . Soil temperature data were not reported and the experiment was not controlled for total fluence rate. However, the differences in global PAR and B light between covers that produced $\mathrm{R}$ : FR ratios of 0.78 and 1.03 were probably not very large.

The conclusion of this section is that manipulation of neighbor photodetection mechanisms in cultivated plants has the potential to increase harvestable yields. However, it would seem that the direction of this manipulation (i.e., toward increased or decreased sensitivity in neighbor-photodetection mechanisms) and the responses for which photocontrol should be manipulated (e.g., branching, fruit abortion) are species-specific and depend on the agronomic situation and production goals.

Caveats about the interpretation of allocation patterns. The above analysis is based on the assumption that characterization of allocation responses and effects on dry weight ratios (e.g., shoot : root ratio), via physiological experiments, is a good starting point to predict the agricultural consequences of photomorphogenic responses to plant density. Several caveats about this assumption should be entered at this point. First, elimination of certain photoresponses can be of agronomic consequence independently of any considerations on allocation tradeoffs. For instance, short-statured plants may be preferred in some crops independently of whether stem elongation competes for assimilates with other growth activities. This preference would be the case for seedlings grown in nurseries or greenhouses to be transplanted to the field (Decoteau and Friend, 1991a), ornamental plants (McMahon and Kelly, 1990; Moe et al., 1991; Rajapakse and Kelly, 1992), and crops susceptible to lodging. Second, a shift in allocation may have different impacts on growth, depending on environment. For instance, the small reduction in root growth observed by some workers in response to FR light (see above) might be inconsequential in all but water- or nutrient-limited growth conditions. In turn, the expression of allocation photoresponses may be strongly conditioned by many environmental factors. Thus, effects of light quality on the shoot : root ratio, which are readily observable in well-watered plants grown in a controlled environment, might be difficult to demonstrate in fieldgrown plants exposed to water and nutrient limitations. Third, the effects of light treatments on an organ's gross morphology or dry weight accumulation may or may not be good predictors of the capacity of that organ to perform a certain function. For instance, gross measurements of root dry weight and dry weight allocation to roots may tell little about the nutrient-acquiring ability of the root system, which might heavily depend on the development of fine, short-lived, (energetically cheap) lateral roots (Fitter, 1994). 


\section{Plant populations}

In the foregoing we have discussed how photomorphogenic mechanisms can affect plant architecture, PAR interception, growth rate, and assimilate allocation. It should be already apparent that the answer to the question, "What would be the agronomic consequences of interfering with the traffic of light signals among neighboring plants?", cannot be general or unqualified. It should also be clear that this question cannot be answered by merely scaling up results from studies on isolated plants. The complexities that characterize the population (or stand) level of organization need to be addressed.

Light capture in a patchy canopy depends heavily on light-driven architectural plasticity. The light environment may be complex and patchy at the scale of the individual plant, even in apparently simple monospecific canopies (Baldocchi and Collineau, 1994). We have discussed in the preceding sections how sensing radial R : FR and B light gradients allows plants to detect the spatial distribution of their neighbors. This information, acquired through phytochromes and specific B-absorbing photoreceptors, triggers phototropic responses that modify shoot geometry and spreading, tracking the spatial distribution of light gaps. Branching responses to canopy heterogeneities are regarded as an important component of plant morphological plasticity, which contributes to the efficient exploitation of canopy gaps (Ballaré, 1994; Hutchings and De Kroon, 1994; Hutchings and Moogie, 1990). In many crops, branching can compensate for missing plants due to sowing defects, hail damage, or low planting density, and that is one of the reasons why branching is regarded as a valuable agronomic trait in marginal or unpredictable cropping environments (Kirby and Faris, 1972). As discussed earlier in this article, light signals play a part in driving branching responses in canopies, as they do in elicitating allometric responses thought to be critical for wholeplant acclimation to changes in light intensity (e.g., changes in leaf area ratio, specific leaf area).

Recent experiments in the field (Ballaré et al., 1995) have shown that wild-type cucumber plants are much more efficient at deploying leaf area into canopy gaps than plants of an isogenic $l h$ mutant that lack immunochemically detectable phytochrome B and that display reduced morphological responses to the proximity of neighboring plants (Ballaré et al., 1991a, 1992a). Although the reasons for this difference may be complex, the observations are consistent with the idea that an impairment in the proximity-sensing mechanisms reduces the ability of the plant to "forage" for light in a patchy canopy. Shoot geometry and space occupation are major determinants of whole-plant growth (Küppers, 1994). Therefore, if we move up in scale one step, i.e., from single shoots to a shoot population, the inference would be that lighttriggered tropic, branching, and allometric responses are likely to be critical for the growing canopy to efficiently fill up the aboveground space. In other words, at each point in time during canopy development, photomorphogenic responses of individual shoots would increase light interception per unit of canopy dry weight. If this is the case, a predictable consequence of eliminating the mechanisms of neighbor photodetection in crops (e.g., either by using extremely high $\mathrm{R}$ : FR ratios in controlled environments or by deliberately breeding insensitive strains) will be to delay the process of gap filling by the crop canopy, with a concomitant reduction in PAR interception. This delay might be quite significant in the case of row crops, where, apart from reducing canopy growth rate, it may encourage weed development.

Photomorphogenic responses reduce plant-to-plant variation in plant populations. Most studies on canopy photomorphogenesis have focused on the average response of the components of a stand, not on the variation among individual plants. The development of size (dry weight) inequalities among neighbors is one of the best characterized population responses to increased planting density (Harper, 1977; Weiner, 1985). Because reproductive output and size are often positively correlated within plant populations (Hedley and Ambrose, 1981; Thompson et al., 1991), understanding the determinants of size variability is of fundamental importance for ecologists (Weiner, 1985; Weiner et al., 1990) and growers (Benjamin and Hardwick, 1986; Donald, 1963; Harper, 1977; Hedley and Ambrose, 1981). In many crops, the density that produces the highest harvestable (commercial) yield is lower than the one that gives the highest biological yield (total crop biomass), which usually reaches a plateau and remains constant over a wide range of planting densities (references in Harper, 1977; Hedley and Ambrose, 1981; Puckridge and Donald, 1967) (Fig. 8, top and middle). Hedley and Ambrose (1981) have shown that, in pea (Pisum sativum L.) crops, an increase in plant density causes a large increase in the coefficient of variation of seed production per plant (Fig. 8, bottom). In a high-density commercial crop, more than $30 \%$ of the plants that contributed to canopy biomass contributed nothing to seed yield. Moreover, within the subpopulation that did reproduce (i.e., the remaining 70\%), the plants that ranked at the lowest end of the size distribution had the lowest harvest indexes. Therefore, the presence of suppressed small plants, which do not actually flower or deploy biomass into harvestable organs, is one of the factors respon-
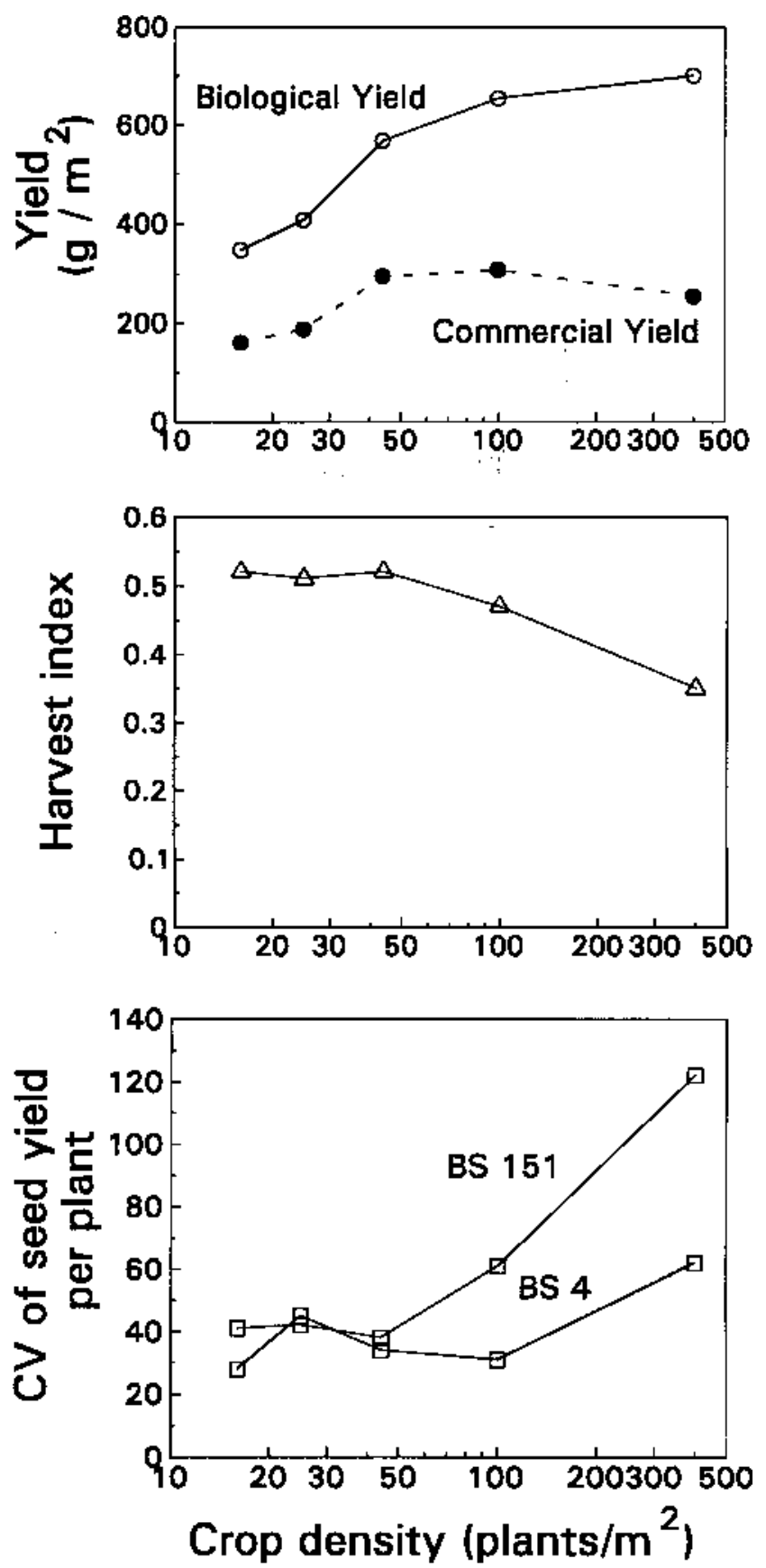

Fig. 8. Effects of increasing crop density on (top) biological and commercial yield, (center) harvest index, and (bottom) the coefficient of variation (cv) of seed count per plant in ("leafless") dried pea grown in the field. Data are means of three genotypes (yield and harvest index) or individual values for two genotypes (cV of seed production) (adapted from Hedley and Ambrose, 1981). 
sible for the decline in crop harvest index at high densities (Fig. 8, top and middle) (Hedley and Ambrose, 1981).

A homozygous line of transgenic tobacco that expresses an oat phytochrome gene ( $p h y A)$ under a constitutive viral promoter and displays altered photophysiology has been used recently to test the role of light sensing in the genesis of size inequalities in plant stands (Ballaré et al., 1994). PhyA-overexpressing transgenic plants showed little or no morphological responsivity to added FR radiation or to the proximity of neighboring plants in spacing experiments (Ballaré et al., 1994; Casal and Sánchez, 1994). In transgenic monocultures, an increase in stand density caused the small plants of the population to be rapidly suppressed by their neighbors (Fig. 9). In wild-type monocultures, plants responded to increased density with large morphological changes, and there appeared to be an inverse relationship between the magnitude of this morphological response and the ranking of the individual plant in the population size hierarchy (data not shown). In these wild-type populations, size inequality increased only moderately with density within the time of the experiments (Fig. 9). These results suggest that, in crowded stands, the ability of individual plants to acquire information about their light environment via phytochrome plays a central role in driving architectural changes that, at the population level, delay the development of size differences among neighbors (Ballaré et al., 1994). The unexpected corollary of these data is that, to the extent that size structuring compromises yield and yield uniformity (see above), elimination of plant photomorphogenic responses in canopies would result in reduced agronomic productivity at high densities.

\section{CONCLUDING ASSESSMENT}

The rapid recent progress in understanding plant photomorphogenesis is leading to a new perception of the mechanism of plant competition. In turn, this improved understanding of the sensory ecology of plants is raising questions that are highly relevant from an agronomic standpoint. In this article, we have centered the discussion around the problem of predicting the consequences of eliminating neighbor photodetection mechanisms in plants. The evidence reviewed is inconsistent with the hypothesis that a nonspecific elimination of proximity-sensing mechanisms will necessarily result in increased harvestable yields by freeing assimilates normally invested by plants in the so-called "shade-avoidance" responses. Except for some very special cases, the expected allocation benefits of this approach are, at best, uncertain. Moreover, there is evidence that, for some crops and under certain agronomic situations, increased yields might result from an increased plant sensitivity to light signals of neighbor proximity.

Experiments also suggest that photomorphogenically "blind" plants are impaired in their ability to efficiently exploit a patchy and highly dynamic light environment. This impairment, when bred into every single plant of a cultivated population, may result in reduced light interception by the crop canopy and reduced crop growth rate. Arguably this reduced light "foraging" efficiency would be of little consequence in densely planted, uniform crops. However, the marked tendency to develop strong size hierarchies in "blind" genotypes will almost certainly reduce yield and yield uniformity at high densities.

Because photomorphogenic processes control key aspects of plant growth and development in canopies, the opportunities for increasing crop yields by manipulating the traffic of light signals among neighboring plants appear to be large. We propose that the key to higher yields lies not in rendering the plant incapable of detecting its neighbors, but in finding out which responses should be controlled and when. Thus, timely light treatments may disable or impair neighbor detection mechanisms only during certain critical developmental phases. For instance, very high R : FR ratios applied only during flowering might prevent abortion of reproductive structures in certain crops without interfering with phytochrome-driven tropic and allometric responses and without causing excessive size structuring during early canopy development. An alternative to targeted manipulation of the light environment that is specially attractive for field crops is the use of developmentally regulated and tissue-specific transgene expression. Directed expression of introduced phytochrome genes to some tissues has already been accomplished. For instance, tobacco
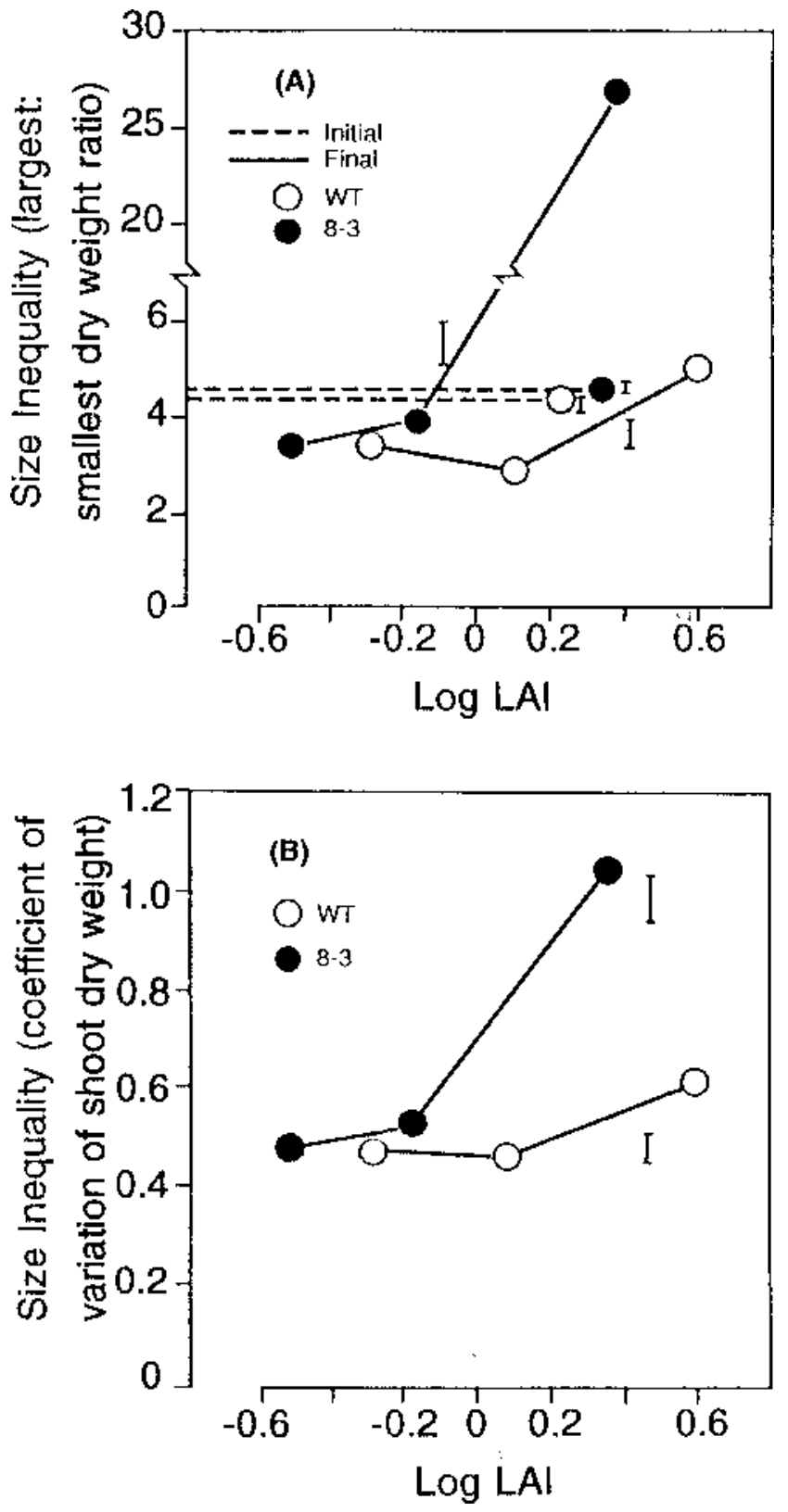

Fig. 9. Effects of increasing population density on the development of size inequalities among neighbors in monocultures of wild type (WT) and 8-3 transgenic tobacco plants. Populations of potted seedlings were grown at three densities under sunlight for 30 days during the summer. At the beginning of the experiment, groups of "small" and "large" plants were identified in each replicate canopy. (A) Dry weight ratio between large and small plant groups in each density treatment (averaged over all replicates) at the end of the experiment. Initial inequality was within $\pm 15 \%$ of the plotted average (dashed line) in all density treatments. (B) Coefficient of variation of individual plant dry weight in each density treatment at the end of the experiment. Data are plotted against the leaf area index estimated for the 15th day (from Ballaré et al., 1994).

transformants have been obtained that express oat phyA under a chlorophyll a/b-binding protein promoter, which expresses mostly in photosynthetically active tissue, and under a ubiquitin extension protein promoter, which tends to concentrate the oat phytochrome in meristematic tissue (E.T. Jordan and R.D. Vierstra, personal communication). Thus, phytochrome constructs may be obtained that only express in certain organs, at certain times during plant development, or under specific environmental circumstances. Plants transformed with these constructs would be expected to display organ-, time-, or environment-specific "blindness" to neighbor proximity photosignals. Also, as we learn more about the transduction chains involved, individual morphogenic processes could be made more or less depen- 
dent of light-sensing mechanisms. A sound understanding of the mechanisms of light signaling among neighboring plants and their agricultural implications will provide the foundation for tailoring plant photophysiology to the needs of each particular crop and cropping environment. This kind of knowledge also will help formulate more accurate models of crop growth (Aikman and Benjamin, 1994) and design multispecies crops in which the timing and intensity of the photomorphogenic interactions among species are adjusted toward a particular production goal.

\section{Literature Cited}

Aikman, D.P. and L.R. Benjamin. 1994. A model for plant and crop growth, allowing for competition for light by the use of potential and restricted projected crown zone areas. Ann. Bot. 73:185-194.

Aphalo, P.J. and C.L. Ballaré. 1995. On the importance of informationacquiring systems in plant-plant interactions. Functional Ecol. 9:5-14.

Aphalo, P.J., D. Gibson, and A.H. DiBenedetto. 1991. Responses of growth, photosynthesis, and leaf conductance to white light and end-of-day red and far-red pulses in Fuschia magellanica Lam. New Phytol. 117:461-471.

Baldocchi, D. and S. Collineau. 1994. The physical nature of solar radiation in heterogeneous canopies: Spatial and temporal attributes, p. 21-71. In: M.M. Caldwell and R.W. Pearcy (eds.). Exploitation of environmental heterogeneity by plants. Academic, San Diego.

Ballaré, C.L. 1994. Light gaps. Sensing the light opportunities in highlydynamic canopy environments, p. 73-110. In: M.M. Caldwell and R.W. Pearcy (eds.). Exploitation of environmental heterogeneity by plants. Academic, San Diego.

Ballaré, C.L., J.J. Casal, and R.E. Kendrick. 1991a. Responses of wild-type and lh-mutant seedlings to natural and simulated shadelight. Photochem. Photobiol. 54:819-826.

Ballaré, C.L., R.A. Sánchez, A.L. Scopel, J.J. Casal, and C.M. Ghersa. 1987. Early detection of neighbour plants by phytochrome perception of spectral changes in reflected sunlight. Plant Cell Environ. 10:551-557.

Ballaré, C.L., R.A. Sánchez, A.L. Scopel, and C.M. Ghersa. 1988. Morphological responses of Datura ferox L. seedlings to the presence of neighbors. Their relationships with canopy microclimate. Oecologia 76:288-293.

Ballaré, C.L., A.L. Scopel, E.T. Jordan, and R.D. Vierstra. 1994. Signaling among neighboring plants and the development of size inequalities in plant populations. Proc. Natl. Acad. Sci. USA 91:10,094-10,098.

Ballaré, C.L., A.L. Scopel, S.R. Radosevich, and R.E. Kendrick. 1992a. Phytochrome-mediated phototropism in de-etiolated seedlings: Occurrence and ecological significance. Plant Physiol. 100:170-177.

Ballaré, C.L., A.L. Scopel, M.L. Roush, and S.R. Radosevich. 1995. How plants find light in patchy canopies. A comparison between wild-type and phytochrome-B-deficient mutant plants of cucumber. Functional Ecol. (In press.)

Ballaré, C.L., A.L. Scopel, and R.A. Sánchez. 1990. Far-red radiation reflected from adjacent leaves: An early signal of competition in plant canopies. Science 247:329-332.

Ballaré, C.L., A.L. Scopel, and R.A. Sánchez. 1991b. Photocontrol of stem elongation in plant neighbourhoods: Effects of photon fluence rate under natural conditions of radiation. Plant Cell Environ. 14:57-65.

Ballaré, C.L., A.L. Scopel, and R.A. Sánchez. 1991c. On the opportunity cost of the photosynthate invested in stem elongation reactions mediated by phytochrome. Oecologia 86:561-567.

Ballaré, C.L., A.L. Scopel, R.A. Sánchez, and S.R. Radosevich. 1992b. Photomorphogenic processes in the agricultural environment. Photochem. Photobiol. 56:777-788.

Barnes, C. and B. Bugbee. 1991. Morphological responses of wheat to blue light. J. Plant Physiol. 139:339-342.

Beltrano, J., J. Willemoës, E.R. Montaldi, and R. Barreiro. 1991. Photoassimilate partitioning modulated by phytochrome in Bermuda grass (Cynodon dactylon (L.) Pers.). Plant Sci. 73:19-22.

Benjamin, L.R. and R.C. Hardwick. 1986. Sources of variation and measures of variability in even-aged stands of plants. Ann. Bot. 58:757-778.

Bernier, G. 1988. The control of floral evocation and morphogenesis. Annu. Rev. Plant Physiol. Plant Mol. Biol. 39:175-219.

Björkman, O. 1981. Responses to different quantum flux densities, p. 57-107. In: O.L. Lange, P.S. Nobel, C.B. Osmond, and H. Ziegler (eds.). Physiological plant ecology I. Responses to the physical environment. vol. NS 12A. Encyclopedia Plant Physiol. Springer Verlag, Berlin.

Blackman, G.E. and G.L. Wilson. 1951. Physiological and ecological studies in the analysis of plant environment. VII. An analysis of the differential effects of light intensity on the net assimilation rate, leaf-area ratio, and relative growth rate of different species. Ann. Bot. 15:374-408.

Bradburne, J.A., M.J. Kasperbauer, and J.N. Mathis. 1989. Reflected far-red light effects on chlorophyll and light-harvesting chlorophyll protein (LHC-
II) contents under field conditions. Plant Physiol. 91:800-803.

Britz, S.J. 1990. Photoregulation of root:shoot ratio in soybean seedlings. Photochem. Photobiol. 52:151-159.

Britz, S.J. and J.C. Sager. 1990. Photomorphogenesis and photoassimilation in soybean and sorghum grown under broad spectrum and blue-deficient light sources. Plant Physiol. 94:448-454.

Bruggink, G.T. and E. Heuvelink. 1987. Influence of light on the growth of young tomato, cucumber and sweet pepper plants in the greenhouse: Effects on relative growth rate, net assimilation rate and leaf area ratio. Scientia Hort. 31:161-174.

Bugbee, B.G. and F.B. Salisbury. 1989. Current and potential productivity of wheat for a controlled environment life support system. Adv. Space Res. 9(8):5-15.

Casal, J.J. 1988. Light quality effects on the appearance of tillers of different order in wheat (Triticum aestivum). Ann. Appl. Biol. 112:167-173.

Casal, J.J. and R. Kendrick. 1993. Impaired phytochrome-mediated shadeavoidance responses in the aurea mutant of tomato. Plant Cell Environ. 16:703-710.

Casal, J.J. and R.A. Sánchez. 1992. Physiological relationships between phytochrome effects on internode extension growth and dry matter accumulation in light-grown mustard. Photochem. Photobiol. 56:571-577.

Casal, J.J. and R.A. Sánchez. 1994. Overexpression of oat phytochrome A gene differentially affects stem growth responses to red/far-red ratio signals characteristic of sparse or dense canopies. Plant Cell Environ. 17:409-417.

Casal, J.J., R.A. Sánchez, and V.A. Deregibus. 1986. Effects of plant density on tillering: The involvement of the R/FR and the proportion of radiation intercepted per plant. Expt. Environ. Bot. 26:365-371.

Casal, J.J., R.A. Sánchez, and V.A. Deregibus. 1987. Tillering responses of Lolium multiflorum plants to changes of red/far-red ratios typical of sparse canopies. J. Expt. Bot. 38:1432-1439.

Casal, J.J., R.A. Sánchez, and D. Gibson. 1990. The significance of changes in red/far-red ratio, associated with either neighbour plants or twilight, for tillering in Lolium multiflorum Lam. New Phytol. 116:565-572.

Child, R. and H. Smith. 1987. Phytochrome action in light-grown mustard: Kinetics, fluence-rate compensation and ecological significance. Planta 172:219-229.

Chow, W.S., D.J. Goodchild, C. Miller, and J.M. Anderson. 1990. The influence of high levels of brief or prolonged supplementary far-red illumination during growth on the photosynthetic characteristics, composition and morphology of Pisum sativum chloroplast. Plant Cell Environ. 13:135-145.

Currah, I.E. and A. Barnes. 1979. Vegetable plant part relationships. I. Effects of time and population density on the shoot and storage root weights of carrot (Daucus carota L.). Ann. Bot. 43:475-486.

Davis, M.H. and S.R. Simmons. 1994. Far-red light reflected from neighbouring vegetation promotes shoot elongation and accelerates flowering in spring barley plants. Plant Cell Environ. 17:829-836.

Decoteau, D.R. and H.H. Friend. 1991a. Growth and subsequent yield of tomatoes following end-of-day light treatment of transplants. HortScience 26:1528-1530.

Decoteau, D.R. and H.H. Friend. 1991b. Phytochrome regulated growth of young watermelon plants. J. Amer. Soc. Hort. Sci. 116:512-515.

Decoteau, D.R., M.J. Kasperbauer, and P.G. Hunt. 1989. Mulch color affects yield of fresh-market tomatoes. J. Amer. Soc. Hort. Sci. 114:216-220.

Donald, C.M. 1963. Competition among crop and pasture plants. Adv. Agron. 15:1-118.

Donald, C.M. 1968. The breeding of crop ideotypes. Euphytica 17:385-403.

Ehrlén, J. 1991. Why do plants produce surplus flowers? A reserve-ovary hypothesis. Amer. Naturalist 138:918-933.

Evans, J.R. 1987. The dependence of quantum yield on wavelength and growth irradiance. Austral. J. Plant Physiol. 14:69-79.

Fitter, H.A. 1994. Architecture and biomass allocation as components of the plastic response of root systems to soil heterogeneity, p. 305-323. In: M.M. Caldwell and R.W. Pearcy (eds.). Exploitation of environmental heterogeneity by plants. Academic, San Diego.

Grime, J.P., J.C. Crick, and J.E. Rincon. 1986. The ecological significance of plasticity. Plasticity in plants. Symp. Soc. Expt. Biol. (UK) 40:5-29.

Guiamet, J.J., J.G. Willemoës, and E.R. Montaldi. 1989. Modulation of progressive leaf senescence by the red:far-red ratio of incident light. Bot. Gaz. 150:148-151.

Harper, J.L. 1977. Population biology of plants. Academic, London.

Hedley, C.L. and M.J. Ambrose. 1981. Designing "leafless" plants for improving yields of the dried pea crop. Adv. Agron. 34:225-277.

Heindl, J.C. and W.A. Brun. 1983. Light and shade effects on abscission and ${ }^{14} \mathrm{C}$-photoassimilate partitioning among reproductive structures in soybean. Plant Physiol. 73:434-439.

Hole, C.C., A. Barnes, T.H. Thomas, P.A. Scott, and W.E.F. Rankin. 1983. Dry matter distribution between shoot and storage root of carrot (Daucus carota L.) I. Effect of variety. Ann. Bot. 51:175-187. 
Hole, C.C., T.H. Thomas, A. Barnes, P.A. Scott, and W.E.F. Rankin. 1984. Dry matter distribution between shoot and storage root of carrot, parsnip, radish and red beet. Ann. Bot. 53:625-631.

Holmes, M.G. and H. Smith. 1977. The function of phytochrome in the natural environment. II. The influence of vegetation canopies on the spectral energy distribution of natural daylight. Photochem. Photobiol. 25:239245.

Hutchings, M.J. and H. De Kroon. 1994. Foraging in plants: The role of morphological plasticity in resource acquisition. Adv. Ecol. Res. 25:159238.

Hutchings, M.J. and M. Moogie. 1990. The spatial structure of clonal plants: Control and consequences, p. 57-76. In: I. van Groenendael and H. De Kroon (eds.). Clonal growth in plants: Regulation and function. SPB Academic Publishing, The Hague, The Netherlands.

Iino, M. 1990. Phototropism: Mechanisms and ecological implications. Plant Cell Environ. 13:633-650.

Kasperbauer, M.J. 1971. Spectral distribution of light in a tobacco canopy and effects of end-of-day light quality on growth and development. Plant Physiol. 47:775-778.

Kasperbauer, M.J. 1992. Phytochrome regulation of morphogenesis in green plants: From the Beltsville spectrograph to colored mulch in the field. Photochem. Photobiol. 56:823-832.

Kasperbauer, M.J. and P.G. Hunt. 1992. Cotton seedling morphogenic responses to FR/R ratio reflected from different colored soils and soil covers. Photochem. Photobiol. 56:579-584.

Kasperbauer, M.J., P.G. Hunt, and R.E. Sojka. 1984. Photosynthate partitioning and nodule formation in soybean plants that received red or far-red light at the end of the photosynthetic period. Physiol. Plant. 61:549-554.

Kasperbauer, M.J. and D.E. Peaslee. 1973. Morphology and photosynthetic efficiency of tobacco leaves that received end-of-day red or far red light during development. Plant Physiol. 52:440-442.

Kirby, E.J.M. and D.G. Faris. 1972. The effect of plant density on tiller growth and morphology in barley. J. Agr. Sci. (Camb.) 78:281-288

Koller, D. 1990. Light-driven leaf movements. Plant Cell Environ. 13:615632.

Körner, Ch. 1991. Some overlooked plant characteristics as determinants of plant growth: A reconsideration. Functional Ecol. 5:162-173.

Küppers, M. 1994. Canopy gaps: Light interception and economic space filling-A matter of whole-plant allocation, p. 111-144. In: M.M. Caldwell and R.W. Pearcy (eds.). Exploitation of environmental heterogeneity by plants. Academic, San Diego.

Kwesiga, F. and J. Grace. 1986. The role of the ref/far-red ratio in the response of tropical tree seedlings to shade. Ann. Bot. 57:283-290.

López-Juez, E., W.F. Buurmeijer, G.H. Heeringa, R.E. Kendrick, and J.C. Wesselius. 1990a. Response of light-grown wild-type and long-hypocotyl mutant cucumber plants to end-of-day far-red light. Photochem. Photobiol. 52:143-150.

López-Juez, E., A. Nagatani, W.F. Buurmeijer, J.L. Peters, M. Furuya, R.E. Kendrick, and J.C. Wesselius. 1990b. Response of light-grown wild-type and aurea-mutant tomato plants to end-of-day far-red light. J. Photochem. Photobiol. Series B. Biology 4:391-405.

McCormac, A., G. Whitelam, and H. Smith. 1992. Light-grown plants of transgenic tobacco expressing an introduced oat phytochrome A gene under the control of a constitutive viral promoter exhibit persistent growth inhibition by far-red light. Planta 188:173-181.

McMahon, M.J. and J.W. Kelly. 1990. Influence of spectral filters on height, leaf chlorophyll, and flowering of Rosa $\times$ hybrida "Meirutral". J. Environ. Hort. 8:209-211.

Méthy, M., P. Alpert, and J. Roy. 1990. Effects of light quality and quantity on growth of the clonal plant Eichhornia crassipes. Oecologia 84:265-271.

Méthy, M.P. and J. Roy. 1993. Morphogenetic changes induced by a low red:far-red ratio and their growth consequences in water hyacinth (Eichhornia crassipes). J. Expt. Bot. 44:1275-1280.

Moe, R., R.D. Heins, and J. Erwin. 1991. Stem elongation and flowering of the long-day plant Campanula isophylla Moretti in response to day and night temperature alterations and light quality. Scientia Hort. 48:141-151.

Mondal, M.F., J.L. Brewster, G.E.L. Morris, and H.A. Butler. 1986a. Bulb development in onion (Allium cepa $\mathrm{L}$.) I. Effects of the plant density and sowing date in field conditions. Ann. Bot. 58:187-195.

Mondal, M.F., J.L. Brewster, G.E.L. Morris, and H.A. Butler. 1986b. Bulb development in onion (Allium cepa L.) III. Effects of the size of adjacent plants, shading by neutral and leaf filters, irrigation and nitrogen regime and the relationship between red:far-red spectral ratio in the canopy and leaf area index. Ann. Bot. 58:207-219.

Montaldi, E.R. 1969. Gibberellin-sugar interaction regulating the growth habit of bermudagrass (Cynodon dactylon (L.) Pers.). Experientia 25:91-92.

Mor, Y., A.H. Halevy, and D. Porath. 1980. Characterization of the light reaction promoting the mobilizing ability of rose shoot tips. Plant Physiol. 66:996-1000.

Morgan, D.C. and H. Smith. 1978. The relationship between phytochrome photoequilibrium and development in light grown Chenopodium album L. Planta 142:187-193.

Murphy, J.S. and D.D. Briske. 1992. Regulation of tillering by apical dominance: Chronology, interpretative value, and current perspectives. J. Range Mgmt. 45:419-429.

Myers, R.L., W.A. Brun, and M.L. Brenner. 1987. Effect of raceme-localized supplemental light on soybean reproductive abscission. Crop Sci. 27:273277.

Novoplansky, A., D. Cohen, and T. Sachs. 1990a. How portulaca seedlings avoid their neighbors. Oecologia 82:490-493.

Novoplansky, A., T. Sachs, D. Cohen, R. Bar, J. Bodenheimer, and R. Reisfeld. 1990b. Increasing plant productivity by changing the solar spectrum. Solar Energy Materials 21:17-23.

Pearcy, R.W. and D.A. Sims. 1994. Photosynthetic acclimation to changing light environments: Scaling from the leaf to the whole plant, p. 145-174. In: M.M. Caldwell and R.W. Pearcy (eds.). Exploitation of environmental heterogeneity by plants. Academic, San Diego.

Puckridge, D.W. and C.M. Donald. 1967. Competition among wheat plants sown at a wide range of densities. Austral. J. Agr. Res. 18:193-211.

Rajapakse, N.C. and J.W. Kelly. 1992. Regulation of chrysanthemum growth by spectral filters. J. Amer. Soc. Hort. Sci. 117:481-485.

Sánchez, R.A., J.J. Casal, C.L. Ballaré, and A.L. Scopel. 1993. Plant responses to canopy density mediated by photomorphogenic processes, p. 779-786. In: D.R. Buxton, R. Shibles, R.A. Fosberg, B.L. Blad, H.T. Asay, G.M. Paulsen, and R.F. Wilson (eds.). International crop science I. Crop Sci. Soc. Amer., Madison, Wis.

Shibles, R., J. Secor, and D.M. Ford. 1987. Carbon assimilation and metabolism, p. 535-588. In: J.R. Wilcox (ed.). Soybeans: Improvement, production, and uses. 2nd ed. Agron. Monogr. 16. Amer. Soc. Sci.-Crop Sci. Soc. Amer.-Soil Sci. Soc. Amer., Madison, Wis.

Smith, H. 1992. The ecological functions of the phytochrome family. Clues to a transgenic programme of crop improvement. Photochem. Photobiol. 56:815-822.

Smith, H. and G. Withelam. 1987. Phytochrome action in the light-grown plant, p. 289-303. In: M. Furuya (ed.). Phytochrome and photoregulation in plants. Academic, Tokyo.

Solangaarachchi, S.M. and J.L. Harper. 1987. The effect of canopy filtered light on the growth of white clover Trifolium repens. Oecologia 72:372-376.

Taylorson, R.B. and H.A. Borthwick. 1969. Light filtration by foliar canopies: Significance for light-controlled weed seed germination. Weed Sci. 17:4851.

Thompson, B.K., J. Weiner, and S.I. Warwick. 1991. Size-dependent reproductive output in agricultural weeds. Can. J. Bot. 69:442-446.

Tsay, J.S., S. Fukai, and G.L. Wilson. 1987. The response of cassava (Manhiot esculenta) to spatial arrangement and to soybean intercrop. Field Crops Res. 16:19-31.

Tucker, D.J. 1975. Far-red light as a suppressor of side shoot growth in the tomato. Plant Sci. Lett. 5:125-130.

Warrington, I.J., D.A. Rook, D.C. Morgan, and H.L. Turnbull. 1988. The influence of simulated shadelight on growth, development and photosynthesis of Pinus radiata, Agathis australis and Dacrydium cupressinum. Plant Cell Environ. 11:343-356.

Weiner, J. 1985. Size hierarchies in experimental populations of annual plants. Ecology 66:743-752.

Weiner, J., E.B. Mallory, and C. Kennedy. 1990. Growth and variability of crowded and uncrowded populations of dwarf marigolds (Tagetes patula). Ann. Bot. 65:513-524.

Weston, G. 1982. The effects of crowding, daminozide and red to far-red ratios of light on the growth of radish (Raphanussativus L.) J. Hort. Sci. 57:373-376.

Wilson, M.I. and B.M. Greenberg. 1993. Specificity and photomorphogenic nature of ultraviolet-B-induced cotyledon curling in Brassica napus L. Plant Physiol. 102:671-677. 